\title{
Maan orgaaninen fosfori
}

\author{
Helinä Hartikainen \\ Helsingin yliopisto, Soveltavan kemian ja mikrobiologian laitos, PL 2700014 Helsingin yliopisto, \\ email: helina.hartikainen@helsinki.fi
}

\begin{abstract}
Johdanto
Maan orgaanista fosforia ei ole Suomessa tutkittu juuri lainkaan vuoden 1948 jälkeen, jolloin Armi Kaila julkaisi myöhemmin klassikon asemaan nousseen väitöskirjansa. Yleisen arvion mukaan viljelysmaiden pintakerroksen fosforista noin $25-65 \%$ on orgaanisessa muodossa. Vaikka määrällisesti orgaaniset fosforireservit voivat olla siis huomattavan suuret, tietoa niiden kemiallisesta luonteesta, biologisesta käyttökelpoisuudesta ja mahdollisesta hyödynnettävyydestä on hyvin niukasti. Samantapainen tilanne vallitsee muuallakin, sillä analyyttisten ongelmien vuoksi orgaaninen fosfori on koettu tutkimuskohteena paljon hankalammaksi ja epäkiitollisemmaksi kuin epäorgaaninen. Kemiallisen analytiikan kehittymisen myötä orgaanisen fosforin tutkimus on kuitenkin huomattavasti vilkastunut viimeisen kymmenen vuoden aikana. Tutkimusta ovat vauhdittaneet myös havainnot, että maavedessä voi olla huomattavasti enemmän orgaanista ja mikrobiologisesti tuotettua kondensoitunutta fosforia (esim. polyfosfaatit) kuin epäorgaanista liukoista fosforia (esim. Ron Vaz ym. 1993, Shand ym. 1994a,b). Koska kasvit ottavat ravinteensa maavedestä, tämä havainto on herättänyt kysymyksen, miten käyttökelpoisia orgaaniset yhdisteet ovat, miten helposti ne liikkuvat ja huuhtoutuvat syvempiin maakerroksiin tai pintavirtailun mukana vesistöihin.
\end{abstract}

\section{Orgaanisen fosforin lähteet ja reaktiot maassa}

Maahan tulee orgaanista fosforia jonkin verran mikrobien syntetisoimana mutta pääasiassa kasvinjätteiden ja lannan mukana. Sen osuus kasviaineksessa vaihtelee kehitysasteen ja kasvilajin mukaan, lannassa osuuteen vaikuttaa mm. varastointiaika ja mahdollinen kuivikelisäys. Kailan (1948) tutkimuksessa orgaanista fosforia oli viljojen oljissa sekä perunan juurissa ja mukuloissa n. 60\%, apilaheinässä n. $50 \%$ ja kukkivassa herneessä $45 \%$. Karjanlannan fosforista valtaosa on peräisin sonnasta, johon sitä erittyy n. 95\%, ja vain pieni osa jää virtsaan (Safley ym. 1984, ref. Haynes ja Williams 1993).

Mikrobiologinen hajotus ja kemialliset reaktiot pilkkovat maahan joutuneita orgaanisia yhdisteitä epäorgaaniseen muotoon, jolloin vapautunut fosfaatti joutuu alttiiksi tehokkaille kemiallisille pidättymisreaktioille. Pidätyspintoina toimivat rapautumisessa syntyneet raudan ja alumiinin oksidit, joten sitoutuminen on tehokasta varsinkin hienojakoisilla kivennäismailla. On kuitenkin huomattava, että tärkeimmissä orgaanisissa yhdisteissään ( $\mathrm{mm}$. fytiini, nukleotidit, fosfolipidit) fosfori esiintyy ortofosfaattiryhminä, jotka pystyvät sitoutumaan samoille pidätyspinnoille kuin epäorgaaninen fosfori. Maa-hiukkasten pinnoille sitoutuminen tekee aineksesta vaikeammin hajoavaa. Tämä reaktiotaipumus tukee Kailan (1948) olettamusta, että maan orgaaninen fosfori mineralisoituu maassa hitaammin kuin typpiyhdisteet. Mineralisoitunut typpi ei myöskään varastoidu fosforin tapaan, sillä vapautunut $\mathrm{NH}_{4}$ typpi muuttuu helposti nitraatiksi, joka ei lainkaan sitoudu maahan.

Fosforin sitoutuminen heikkenee maan $\mathrm{pH}: n$ noustessa, sillä sitovien oksidien pinnat muuttuvat negatiivisemmiksi, minkä vuoksi ne alkavat enemmän hylkiä negatiivisesti varattua fosfaatti-anionia. Erityisesti urea lisää fosforin vapautumista, sillä se pystyy nostamaan $\mathrm{pH}: \mathrm{n}$ ohimenevästi korkeammalle kuin kalkkikivi ja samalla aiheuttaa myös orgaanisen aineksen liikkeelle lähtöä (Hartikainen ja Yli-Halla 1995). Tämän vuoksi on todennäköistä, että esim. laitumilla virtsalaikkujen kohdalla saattaa tapahtua muutoksia maan orgaanisen aineksen määrässä sekä fosforin sitoutumisessa ja jakautumisessa maaprofiilissa.

\section{Tutkimushankkeen kysymyksenasettelu ja tavoitteet}

Suomalaisissa maissa on Keski- ja Etelä-Euroopan maihin verrattuna runsaasti orgaanista ainesta, sillä kylmä ilmasto, kosteat olosuhteet, maaperän happamuus ja korkea rauta- ja alumiinioksidien pitoisuus hidastavat hajotusta. Näin ollen myös orgaanisen fosforin varastot ovat ilmeisen suuret. Reservien määrästä, niiden luonteesta, käyttökelpoisuudesta kasveille ja huuhtoutumistaipumuksesta ei kuitenkaan ole tarkkaa käsitystä. Epäselvää on myös, miten maan viljelyhistoria ja tuotantotapa (tavanomai 
nen/luomu/karjan laidunnus) vaikuttavat orgaanisen fosforin määrään ja hyödynnettävyyteen. Erityisesti tietoa kaivataan luomuviljelyssä, jossa fosforin saatavuus voi ajan mittaan muodostua ongelmalliseksi tekijäksi, joka heikentää sadon määrää ja laatua. Tilatasolla kierrosta poistuu fosforia, jonka määrä riippuu tuotantosuunnasta. Luomuviljelyssä sallittu raakafosfaatti on varsin tehoton lannoitteena erittäin huonon liukoisuuden takia. Tavanomaisessa viljelyssä olisi myös tärkeää tietää, tulisiko orgaaniset reservit ottaa huomioon esim. lannoitussuosituksia tehtäessä.

Joillakin valuma-alueilla saattaa jopa $75 \%$ vuosittaisesta fosforikuormituksesta olla peräisin pelloilta, jotka muodostavat vain 5\% valuma-alueilla pinta-alasta (esim. Sharpley ja Rekolainen 1997). Näiden alueiden tunnistaminen olisi tärkeää, jotta kalliit vesiensuojelutoimenpiteet osattaisiin kohdentaa oikein ja niistä saataisiin mahdollisimman suuri hyöty. Euroopan Unionin maissa ja muualla on kehitelty metodeja näiden kriittisten alueiden tunnistamiseksi. Riskinarvioinnissa käytetään yleisesti maan fosforin kyllästysasteen mittaamista. Mielenkiintoista on havaita, että yhteistä näille metodeille on, että niissä on jätetty orgaaninen fosfori ottamatta huomioon (ks. Chardon ja van Faassen 1999).

Vuonna 2002 käynnistettiin yhteistutkimus (Helsingin yliopisto, MTT ja SYKE), jossa ryhdyttiin selvittämään mm. seuraavia käytännön kannalta tärkeitä näkökohtia:

- miten paljon ja millaisessa muodossa erityyppisissä maissa on orgaanista fosforia

- miten viljelytapa (tavanomainen/luomu) vaikuttaa orgaanisiin reserveihin

- onko lannan ja mineraalilannoitteiden fosforin liikkumisessa eroja

- miten laidunnus vaikuttaa fosforin jakautumiseen maaprofiilissa (virtsa/sonta)

- pystyvätkö kasvit hyödyntämään orgaanista fosforia (astiakoe, hajoavuustestit)

- miten orgaaninen fosfori uuttuu erilaisissa neuvonnallisissa testeissä

\section{Menetelmät}

Koska valmiita rutiinimenetelmiä ei ole, aluksi tehtiin analyysimenetelmien kehittelytyötä, lähinnä teknisten ongelmien ratkaisemiseksi. Tämän jälkeen selvitettiin orgaanisen fosforin kokonaismäärää tavanomaisella polttomenetelmällä (Kuo 1996) ja tuloksia vertailtiin muunnellussa Changin ja Jacksonin (Hartikainen 1979) sekä Hedleyn ym. (1982) fraktioinnissa peräkkäisissä uutoissa saatuun kokonaismäärään. Changin ja Jacksonin $(\mathrm{C} \& \mathrm{~J})$ menetelmässä erotellaan toisistaan alumiini- $\left(\mathrm{NH}_{4} \mathrm{~F}\right.$-uutto) ja rautaoksidien (NaOH-uutto) sekä apatiittisessa muodossa $\left(\mathrm{H}_{2} \mathrm{SO}_{4}\right)$ oleva fosfori. Happoliukoisen fraktion katsotaan edustavan kasveille käyttökelvottomia varoja, mutta muuta tietoa käyttökelpoisuudesta menetelmä ei anna. Hedleyn ym. menetelmä puolestaan perustuu ajatukselle, että peräkkäisissä uutoissa saadut fraktiot edustavat käyttökelpoisuudeltaan asteittain huononevia pooleja: $\mathrm{H}_{2} \mathrm{O}-\mathrm{P}$ helposti liikkuva, käyttökelpoinen; $\mathrm{NaHCO}_{3}-\mathrm{P}$ helposti mobilisoituva; $\mathrm{NaOH}-\mathrm{P}$ hitaasti mobilisoituva; HCl-P käyttökelvoton. Se ei kuitenkaan anna tietoa siitä, mistä kemiallisesta fraktiosta uuttuneet varat ovat peräisin. Fraktiointianalyysien lisäksi tehtiin erityyppisiä neuvonnallisia analyysejä ja mitattiin niissä uuttuneita orgaanisen fosforin määriä: Suomessa käytettävä hapan asetaattiuutto (Paac, Vuorinen \& Mäkitie 1955; $\mathrm{NaHCO}_{3}$-uutto pH 8.2, Olsenin testi (Olsen ja Sommers 1982), vesiuutto.

\section{Alustavia tuloksia}

\section{Orgaaninen fosfori ja maan viljelyhistoria}

Maan ottaminen viljelyyn parantaa orgaanisen aineksen hajotusolosuhteita, kun maata muokataan, kalkitaan, sitä aletaan lannoittaa ja tehdään ojitustöitä. Luonnontilaisissa kivennäismaissa orgaanisen aineksen hajotuksen ja tuoton välillä vallitsee melko vakaa tasapaino, joka viljelyyn oton seurauksena muuttuu. Karikeaineksen laatu ja viljelykäytännöt puolestaan vaikuttavat siihen, mille tasolle uusi tasapaino hajotuksen ja tuoton välillä asettuu.

Maan orgaanisten fosforireservien suuruutta ja viljelyhistorian vaikutusta niihin selvitettiin Jokioisten Yönin tilalta otetulla maanäytesarjalla, joka edusti jatkumoa: metsä, viljelemätön niitty, luonnonmukaisesti viljelty karjanlantaa saanut pelto ja tavanomaisesti viljelty pelto. Näytteiden väliset erot lajitekoostumuksessa (55-65\% savesta) ja erityisesti fosforia pidättävien oksidien määrissä olivat pieniä. Taulukon 1 tuloksista nähdään, että karikekerroksen alapuolella olevassa metsämaassa hiilipitoisuus oli melko korkea. Kaikkein suurimmat hiilen ja typen pitoisuudet olivat kuitenkin luonnontilaan jätetyllä niityllä. Sen viljelyyn otto oli vähentänyt sekä hiilen että typen pitoisuutta, mutta luomupellolla lasku oli vähäisempi kuin tavanomaisesti viljellyllä. 
Polttomenetelmä antoi selvästi suurempia (15-57\%) orgaanisen fosforin pitoisuuksia kuin fraktiointianalyysit (taulukko1). Kaikki menetelmät antoivat kuitenkin samanlaisen käsityksen orgaanisen fosforin osuudesta maan fosforireserveistä. Poikkeuksena oli vain tavanomaisesti viljelty pelto, jossa Changin ja Jacksonin fraktiointianalyysi antoi muita pienemmän osuuden. Suurimmat orgaaniset reservit olivat odotusten mukaisesti luonnonniityllä. Niiden määrä näytti laskevan, kun niitty otettiin viljelyyn riippumatta siitä, oliko maa tavanomaisessa vai luomutuotannossa. Metsämaahan verrattuna luonnonniityllä näytti tapahtuneen orgaanisen fosforin kertymistä. Suhteellisesti voimakkainta kertyminen oli Al:n sitomaan $\left(\mathrm{NH}_{4} \mathrm{~F}-\mathrm{P}\right)$ fraktioon (taulukko 2). Kaikissa maissa kuitenkin pääosa orgaanisesta fosforista oli raudan sitomassa (NaOH-P) fraktiossa (taulukko 2) kuten epäorgaaninenkin. Kummallakaan fraktiointimenetelmällä ei orgaanista fosforia löytynyt happoliukoisesta fraktiosta.

Taulukko 1. Orgaaninen hiili ja typpi sekä fosforin kokonaismäärä (mg/kg) ja \%-osuus kokonaismäärästä eri menetelmillä mitattuna Yönin tilan näytteissä.

\begin{tabular}{|c|c|c|c|c|c|c|c|c|}
\hline & \multirow{2}{*}{$\begin{array}{c}\text { Org. C } \\
\%\end{array}$} & \multirow{2}{*}{$\begin{array}{c}\text { Org. N } \\
\%\end{array}$} & \multicolumn{2}{|c|}{ Polttomenetelmä } & \multicolumn{2}{|c|}{ Ghang\& Jackson } & \multicolumn{2}{|c|}{ Hedley } \\
\hline & & & Org. P & $\%$ & Org. P & $\%$ & Org. P & $\%$ \\
\hline Metsä & 4.9 & 0.31 & 452 & 54 & 335 & 55 & 344 & 54 \\
\hline Luonnonniitty & 5.2 & 0.37 & 641 & 66 & 479 & 62 & 482 & 59 \\
\hline Luomu & 4.4 & 0.32 & 496 & 53 & 372 & 52 & 408 & 51 \\
\hline Tavanomainen & 3.6 & 0.26 & 466 & 52 & 295 & 44 & 405 & 50 \\
\hline
\end{tabular}

Taulukko 2. Orgaanisen fosforin jakautuminen ( $\mathrm{mg} / \mathrm{kg}$ ) Changin ja Jaksonin fraktioinnissa alumiinin (Al-P) ja raudan (Fe-P) oksidien sitomiksi oletettuihin fraktioihin sekä Hedleyn menetelmän eri uuttoliuoksiin.

\begin{tabular}{|c|c|c|c|c|c|}
\hline & \multicolumn{2}{|c|}{ Chang \& Jackson } & \multicolumn{3}{|c|}{ Hedley } \\
\hline & $\begin{array}{c}\mathrm{Al}-\mathrm{P} \\
\left(\mathrm{NH}_{4} \mathrm{~F}\right)\end{array}$ & $\begin{array}{c}\mathrm{Fe}-\mathrm{P} \\
(\mathrm{NaOH})\end{array}$ & $\mathrm{H}_{2} \mathrm{O}$ & $\mathrm{NaHCO}_{3}$ & $\mathrm{NaOH}$ \\
\hline Metsä & 24 & 308 & 6.9 & 59 & 251 \\
\hline Luonnonniitty & 64 & 413 & 2.7 & 67 & 388 \\
\hline Luomu & 33 & 337 & 4.7 & 45 & 328 \\
\hline Tavanomainen & 32 & 261 & 3.2 & 39 & 328 \\
\hline
\end{tabular}

\section{Orgaanisen fosforin uuttuminen testeissä}

Käytännön tarpeita varten on kehitelty erilaisia fosforitestejä, jotka voivat merkittävästi poiketa toisistaan uuttoliuoksen kemiallisen luonteen, happamuuden sekä uuttosuhteen osalta. Kaikille käytössä oleville menetelmille ei välttämättä löydy teoreettisia perusteita ja niiden antamien tulosten tulkinta lannoitustarvetta määritettäessä perustuu pitkäaikaiseen kokemukseen. Yhteistä kuitenkin on, että fosforitilan määrittely perustuu epäorgaanisen fosforin mittaukseen. Taulukossa 3 esitetyt tulokset osoittavat kuitenkin, että käytetyt liuokset uuttavat huomattavia määriä myös orgaanista fosforia.

Taulukko 3. Epäorgaanisen ja orgaanisen fosforin uuttuminen $(\mathrm{mg} / \mathrm{kg})$ eri testeissä ja orgaanisen fosforin $\left(\mathrm{P}_{\mathrm{o}}\right)$ osuus uuttuneesta kokonaismäärästä viljelyhistorialtaan erilaisissa maissa.

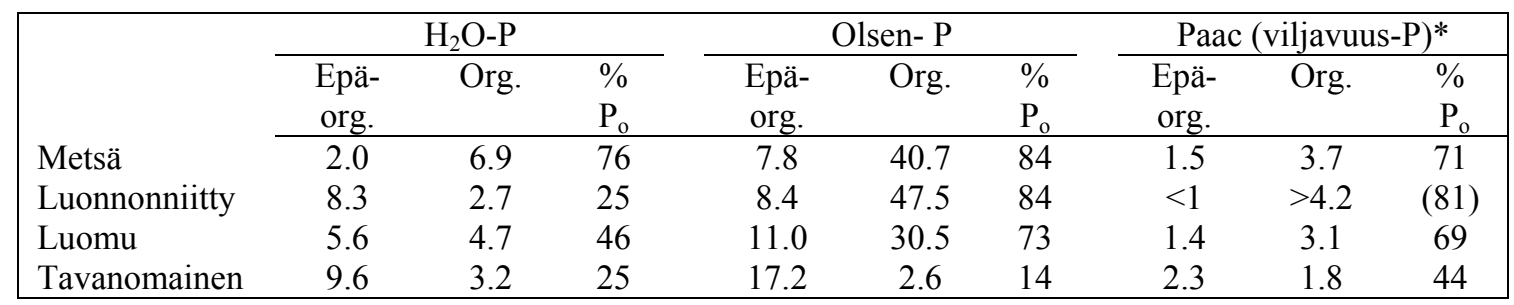

* = mg/l maata

Kalkkipitoisille maille kehitetty Olsenin testi antoi suurimmat fosforitulokset, sillä uuttoliuoksen korkea $\mathrm{pH}$ edistää epäorgaanisen fosforin desorptiota oksidipinnoilta ja humus- ym. orgaanisten yhdisteiden liukoisuutta. Vesi uutti sekä epäorgaanista että orgaanista fosforia selvästi enemmän kuin hapan viljavuusuutto. Myös maiden väliset erot olivat selkeämpiä vesiuutossa. Jos käytössä olevassa vilja 
vuustestissä otettaisiin huomioon orgaaninen fosfori, joissakin taulukon 3 maissa viljavuusluokka paranisi yhden tai kahden luokan verran.

\section{Lannoitustavan vaikutus maan fosforireserveihin}

Epäorgaaninen fosfori pyrkii sitoutumaan rapautumisen tuottamien oksidien pinnoille. Samoista pidättymispaikoista kilpailevat myös mm. humuksen happojen anionit. Oksidien pintojen täyttyessä ja kilpailun kasvaessa fosforin sitoutumislujuus heikkenee. Samalla sen biologinen käyttökelpoisuus paranee, mutta myös liikkumisherkkyys lisääntyy.

Pohjanmaalta kerätyn aineiston avulla selvitettiin fosforin jakautumista maaprofiilissa viljely- ja lannoitushistorialtaan erilaisissa maissa (tiedot perustuvat haastatteluihin). Aineisto koostui 12 lohkoparista, joista toista oli lannoitettu mineraalilannoitteilla ja toista pääsääntöisesti lannalla. Orgaanisen hiilen määrään ei lantakäsittelyllä näyttänyt olevan vaikutusta. Lantaa saaneilla lohkoilla lisätyn fosforin määrä oli keskimäärin 1,7-kertainen mineraalilannoitetta saaneisiin verrattuna, mikä kasvatti lähinnä niiden epäorgaanisia reservejä erityisesti ylimmässä maakerroksessa. Näyttää siltä, että mitä enemmän maassa on orgaanista ainesta, sitä syvemmällä on havaittavissa epäorgaanisten fosforivarojen kasvua. Lantakäsittelyn aiheuttamat muutokset olivat selvästi pienempiä orgaanisen fosforin määrissä. Tulos viittaa siihen, että lannan fosfori hajoaa tehokkaasti epäorgaaniseen muotoon.

\section{Jatkotutkimukset}

Alustavien havaintojen varmentamiseksi tehdään tarkempia jatkoselvityksiä mm. viljelytavan vaikutuksesta maan orgaanisiin fosforivaroihin. Kuluvan vuoden ohjelmaan kuuluu osatutkimus, jossa selvitetään kasvien kykyä hyödyntää orgaanisia reservejä. Se toteutetaan astiakokeena, koska astioihin muodostuvan runsaan juuriston vuoksi kasvien ravinteiden otto maasta on hyvin tehokasta ja mahdolliset muutokset reserveissä on helpompi havaita. Orgaanisten yhdisteiden biologista käyttökelpoisuutta arvioidaan kemiallisten ja biokemiallisten testien avulla. Systemaattisessa laidunkokeessa (Perttu Virkajärven koordinoima hankekokonaisuus) seurataan sonnan ja virtsan vaikutusta fosforin esiintymismuotoihin ja jakautumiseen maaprofiilissa eri syvyyksillä. Lisäksi selvitetään orgaanisen fosforin osuutta helppoliukoisten fosforivarojen lisääjänä.

\section{Kirjallisuus}

Chardon. W.J. \& van Faassen, H.G. 1999. Soil indicators for critical source areas of phosphorus leaching. Wageningen: The Netherlands Integrated Soil Research Programme/vol 22. ISBN 90-73270-37-5.

Hartikainen, H. \& Yli-Halla, M. 1995. Solubility of soil phosphorus as influenced by urea. Z. Pflanzenernähr. Bodenk. 159: 327-332.

Haynes, R.J. \& Williams, P.H. 1993. Nutrient cycling and soil fertility in the grazed pasture ecosystems. Advances in Agronomy 49: 119-199.

Hedley, M.J, Stewart, J.W.B. \& Chauhan, B.S. 1982. Changes in inorganic and organic soil phosphorus fractions induced by cultivation practices and by laboratory incubations. Soil Sci. Soc. Am. J. 46: 970-976.

Kaila, A. 1948. Viljelysmaan orgaanisesta fosforista. Valtion maatalouskoetoiminnan julkaisuja 129.

Kuo, S. 1996. Phosphorus. S. 869-919 teoksessa Methods of soil analysis. Part 3. Chemical methods. Madison, Wisconsin. Soil Science Society of America, Inc.

Olsen, S.R. \& Sommers, L.E. 1982. Phosphorus. Sivut 403-430 teoksessa Methods of soil analysis. Part 2. Chemical and microbiological properties. Agronomy Monograph 9. $2^{\text {nd }}$ edition. Madison, Wisconsin. American Society of Agronomy.

Ron Vaz, M.D., Edwards, A.C., Shand, C.A. \& Cresser, M.S. 1993. Phosphorus fractions in soil solution: Influence of soil acidity and fertilizer additions. Plant Soil 148: 175-183.

Safley, L.M., Barker, J.C. ja Westerman, P.W. 1984. Trans. ASAE 27: 1150-1153.

Shand, C.A., Macklon, A.E.S., Edwards, A.C. \& Smith, S. 1994a. Inorganic and organic P in soil solutions from three upland soils. I Effect of soil solution extraction conditions, soil type and season. Plant Soil 159: 255264.

Shand, C.A., Macklon, A.E.S., Edwards, A.C. \& Smith, S. 1994b. Inorganic and organic P in soil solutions from three upland soils. II Effect of defoliation and fertilizer application. Plant Soil 160: 160-171.

Sharpley, A.N. \& Rekolainen, S. 1997. Phosphorus in agriculture and its environmental implications. Teoksessa: Tunney, H., Carton O.T., Brookers, P.C. \& Johnson, A.E. (toim.): Phosphorus loss from soil to water: 391-394. ISBN 0851991564.

Vuorinen, J. \& Mäkitie, O. 1955. The method of soil testing in use in Finland. Agrogeological Publication 63: $1-44$. 